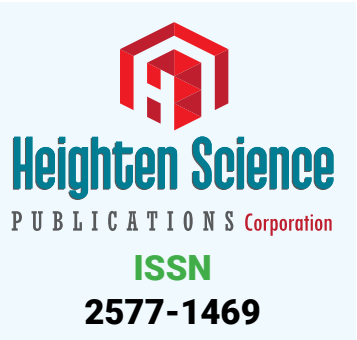

*Address for Correspondence: Bernard J Van Wie, Gene and Linda Voiland School of Chemical Engineering and Bioengineering, Washington State University, Pullman, Washington, Zip Code: 99164-6515, USA, Tel: +1-509-335-4103; Email: bvanwie@wsu.edu

Submitted: 01 May 2018

Approved: 12 June 2018

Published: 13 June 2018

Copyright: @ 2018 Nazempour A, et al. This is an open access article distributed under the Creative Commons Attribution License, which permits unrestricted use, distribution, and reproduction in any medium, provided the original work is properly cited

Keywords: Articular cartilage repair; Centrifugal bioreactor; Chondrogenesis; Mechanical stimulation; Perfusion; Oscillating hydrostatic pressure

Check for updates
Procedure

\section{A flow perfusion bioreactor with controlled mechanical stimulation: Application in cartilage tissue engineering and beyond}

\author{
Arshan Nazempour and Bernard J Van Wie* \\ Gene and Linda Voiland School of Chemical Engineering and Bioengineering, Washington State \\ University, Pullman, Washington, Zip Code: 99164-6515, USA
}

\section{Abstract}

To repair articular cartilage (AC) defects in osteoarthritic patients, one approach is to engineer threedimensional grafts with physicochemical properties similar to endogenous AC. Such grafts can be grown in bioreactors that provide environmental conditions favoring chondrogenesis. Studies show mechanical stimulation during the culturing process greatly enhances development of functional engineered grafts. A review of literature on bioreactor options reveals a lack of capacity to simultaneously stimulate cells with a combination of shear stress and oscillating hydrostatic pressure, both of which are important parts of the in vivo AC environment. It is hypothesized that combining both forces in a new bioreactor design will contribute to better AC tissue growth. In this paper, we provide a brief review of bioreactors and describe a new computer-controlled perfusion and pressurized bioreactor system, and the novelty of its control programming features for service in a host of applications. We briefly summarize results on synergistic effects in employing perfusion, oscillating hydrostatic pressure in a scaffold free environment and with the addition of encapsulation for inducing chondrogenesis. We further describe efforts to modify the newly developed system to include a continuous flow and pressurized centrifugal mode to enhance further the capabilities for inclusion of very high shear stresses. Applications for several other cell and tissue engineering approaches are discussed.

\section{Introduction}

Articular cartilage (AC) is a semitransparent, strong connective tissue that covers the articulating surfaces of bones [1]. It contains a rubbery matrix with extensive amounts of water, collagen, and proteoglycan fibers [2], and its unique structure allows it to absorb mechanical loads while creating a near-frictionless environment in articulating joints [3]. However, because AC is avascular and aneural, it has poor intrinsic ability for self-repair after injury [4]. Damage to AC is progressive and leads to osteoarthritis, a condition that affects 5 percent of the general population and 70 percent of those over age of 65 , and costs nearly $\$ 8$ billion annually in health care expenses [5]. Due to the socioeconomic and human impacts of this condition there has been a concerted effort to develop innovative strategies to repair damaged AC. One promising approach is the use of grafts comprised of replacement $\mathrm{AC}$ tissue, engineered to have properties similar to endogenous AC.

To create such grafts a variety of in vitro culturing techniques have been investigated. Monolayer cultures were first. However, cell types used in AC tissue engineering (ACTE), which most notably include articular chondrocytes (AChs) and mesenchymal stem cells (MSCs), tend to lose their morphology and their ability to secrete extracellular matrix (ECM) specific to AC when they are cultured in monolayers [6-8]. Researchers moved to pellet and micromass culture, providing three-dimensional environments allowing cell-to-cell interactions similar to pre-cartilage condensations found during embryonic 
development [9]. Pellet and micromass culturing have become standard procedures for investigating the growth of engineered AC tissue. However, these techniques are difficult to scale up, and the small-scale tissue constructs produced cannot be applied for the repair of cartilage defects [10]. Moreover, because mass transfer in these approaches relies solely on diffusion, cell apoptosis occurs in the central region of the matrix [11].

To alleviate these problems researchers have begun to develop larger-scale bioreactors that can provide more ideal environments conducive to AC tissue growth.

This paper provides a brief review of various bioreactor systems that were previously developed for ACTE and we discuss their advantages and drawbacks. Then, we describe a novel perfusion/pressurized bioreactor system developed by the authors to move this technology forward and provide enhanced capacities for the development of AC tissues. Then we briefly discuss our efforts to modify the new perfusion/pressurized bioreactor to be run in a centrifugal mode and discuss results from previous publications and its relevance in guiding future work.

\section{Bioreactors for articular cartilage tissue engineering}

Spinner flask: In ACTE a spinner flask starts with cell-seeded scaffolds attached to needles and suspended in culture medium agitated by a magnetic stirrer placed. Usually $50 \%$ of the culture medium is replaced every two days $[12,13]$ and the procedure induces chondrogenesis in AChs, MSCs, and co-cultures of both [14]. In one study with bovine AChs (bAChs), seeded into polyglycolid acid (PGA) scaffolds, culture results in cartilage constructs with $70 \%$ more cells, $60 \%$ more glycosaminoglycogen (GAG), and 125\% more collagen compared to a petri dish [15]. In another, adipose derived stem cells (ADSCs), inoculated into chitosan/gelatin hybrid hydrogels, and secreted significantly more proteoglycan in a spinner flask than in a static T-75 flask, as evidenced by stronger Alcian blue and Safranin 0 staining [16]. Spinner flasks also successfully induce both chondrogenesis and osteogenesis in bone-marrow-derived MSCs (BMSCs) [17-19]. Despite their benefits, spinner flasks can create turbulent flow and high shear stresses at construct surfaces, leading to formation of fibrous capsules on the surface [20]. Though spinner flasks reduce external diffusion limits, they do not provide significant mass transport, i.e., growth medium cannot penetrate well within the porous network leading to significant cells death in the center of scaffolds [21-23].

Rotating wall vessel: Rotating wall vessels (RWV) were developed by NASA, to protect cells from high g-forces during space-shuttle takeoffs and landings [24]. The vessel consists of two cylinder chambers in which both inner and outer walls rotate independently at constant angular speeds. Gas exchange is provided by a membrane. There are two primary designs: slow turning lateral vessels (STLVs) and high aspect ratio vessels (HARVs) [25,26]. In both, cells seeded into micro-carrier beads [27] or porous scaffolds [28] experience three different forces: $\operatorname{drag}\left(\mathrm{F}_{\mathrm{d}}\right)$, centrifugal $\left(\mathrm{F}_{\mathrm{c}}\right)$, and gravitational $\left(\mathrm{F}_{\mathrm{g}}\right)$. These cancel each other and keep the suspension in free-fall state. The HARV lowers the speed necessary to keep constructs stationary and enhances gas exchange.

In RWV, exposure to laminar flow reduces the boundary layer surrounding cells and enhances mass transfer rate. Using an RWV environment, cartilage tissue of $5 \mathrm{~mm}$ thickness has been grown both on Earth and on the Space Station Mir within seven months [29]. Ohyabu and colleagues [30] used cultured rabbit BMSCs without a scaffold, and obtained cartilaginous constructs with higher expression of GAG and Col II compared to pellets. Human BMSCs cultured in an RWV without a scaffold, resulted in statistically significantly higher concentrations of GAG and Col II compared to pellets [31]. Yoshioka and colleagues [32] reported successful regeneration of cartilage in osteochondral-defective Japanese white rabbits using cartilaginous constructs 
obtained from culturing BMSCs. Yoshioka and colleagues culturing human BMSCs on a silk scaffold for 5 weeks produced $8 \mathrm{~mm}$ diameter by $2 \mathrm{~mm}$ thick cartilaginous constructs [33].

Rotating shaft bioreactor: Rotating shaft bioreactors (RSBs) consist of a waterjacketed glass cylinder, a sealing cap assembly, and a stainless shaft on which 22-G needles are soldered [34]. Cell-seeded scaffolds are positioned on the individual needles. The RSB is usually oriented horizontally and then half of the reactor space is filled with growth medium. The reactor is operated in a perfusion mode with the shaft rotation speed maintained at a constant RPM. The rotation moves the constructs between gas and liquid phases in an alternating fashion, which allows for gas and nutrient exchanges. The direction of rotation (clockwise and counterclockwise) is switched daily so that the construct grows in a uniform fashion [35]. Rat AChs incubated into poly (L-lactide-co-glycolide) scaffolds and maintained in an RSB environment showed closer similarity to native rat cartilage in terms of cell volume, spatial distribution, and morphology, based on haemotoxylin and eosin staining and stained stronger for type II collagen, when compared to samples from spinner flasks [36]. These results seem promising, but more research needs to be done to find the optimum rotation speed, medium, and gas-flow rate, and to compare the results against other bioreactor environments.

Wave bioreactor: The wave bioreactor has been used for recombinant NS0 cells for monoclonal antibody production, adenovirus production using human 293 cells, Sf9 insect cell/baculovirus, and human 293 cells on a microcarrier [37,38]. It consists of a sterilized plastic chamber on a mobile platform, partially filled with growth medium and partially with gas, so up- and down movements make waves at the liquidair interface increasing mass transport through the constructs. They have been used for producing MSCs in large quantities [39], but not yet for chondrogenesis.

Flow perfusion bioreactor: Bioreactors above are limited in ability to perfuse medium into the scaffold core. Perfusion bioreactors consist of a chamber where medium perfuses through the scaffold. Perfusion bioreactors decrease the inner and outer mass-transfer boundary layers and improve cell viability [40]. Human BMSCs seeded into chitosan scaffolds stained stronger with Toluidine Blue and Safranin O revealing higher ECM production [41]. Ovine AChs in PGA scaffolds show 45\% more cell content [42]. BAChs seeded into poly-L-lactic acid/PGA scaffolds demonstrate a $118 \%$ increase in DNA content and $184 \%$ increase in GAG content [43]. Santoro and colleagues [44] uniformly seeded hAChs into $50 \mathrm{~mm}$ diameter by $3 \mathrm{~mm}$ thick Hyaff- 11 scaffolds, and after two weeks, obtained homogeneous cartilaginous constructs with biochemical and mechanical properties close to native cartilage and cells and GAG were distributed more homogenously.

Although promising results are shown [45-47], future studies are recommended to clarify the exact underlying molecular mechanisms affected by enhancement of masstransfer. Moreover, medium flow over or through newly formed cartilage constructs may wash out ECM components and future studies should explore this. More complicated flow patterns should be investigated to obtain optimum chondrogenesis. Shahin and colleagues [48], provide an initial investigation into this topic by seeding hAChs into PGA scaffolds and found GAG concentration superior in the low and gradually-increasing-flow-rate alternatives.

Tubular perfusion bioreactor: The tubular perfusion bioreactors (TPBs) [49], are easily fabricated allowing cell construct encapsulatation in tightly packed spherical beads [50]. One study found hBMSCs encapsulated in alginate beads had 1.6 times more cells [49]. Others found hBMSCs secrete more GAGs in the dynamic environment of a TPB as evidenced by Alcian blue staining [51]. These advantages are likely due to the enhancement in mass transfer caused by perfusion through and around packed scaffolds, which also enhances shear stress. Further work should focus on TPB effectiveness against other perfusion bioreactors. 
Hollow-fiber bioreactor: Hollow fiber bioreactors (HFBs) showed success in increasing human tumor-infiltrating lymphocyte cell density from initial 0.35-10 ' $10^{8}$ to $1.5-5.4^{\prime} 10^{10}$ total cells in 14-32 days period with $91 \%$ cell viability, decreasing expansion time by $80 \%$ [52]. Even flow distribution is obtained within each fiber [53] and extra-capillary flow is supplied by shell ports. A cell-suspension medium is passed through either the extra- or intra-capillary space to provide nutrients with cells seeded inside [54,55], or outside of the fibers [52,56]. HFBs have been successfully used [57-61], and in most experiments, $330 \mu \mathrm{m}, 0.2 \mu \mathrm{m}$ pore, and $150 \mu \mathrm{m}$ wall thickness polypropylene hollow fibers are arranged along the axis of high-purity glass tubing, and were held in place with silicon rubber [54-58]. Potter and colleagues obtained a cartilaginous construct with one millimeter thickness after four weeks in an HFB [57]. They are used for MSC expansion [62-65], and Li and colleagues [66,67], found 50-fold expansion within 7 days maintaining self-renewal and multi-lineage differentiation capacity. Nold and colleagues [68], harvested 2-58 million hBMSCs from 8-30 ml of primary, unprocessed bone marrow aspirate maintaining surface antigen expression, differentiation capacity, and immunosuppressive function. A shortcoming is the gradient in both nutrients and products as a consequence of axial pressure gradients leading to heterogeneous distribution of cells and ECM components [69]. Kim and colleagues [61] found significantly higher PG content in the region near culture medium inflow (45\%) as compared to the outflow region (24.7\%). Another concern is the difficulty in scaling-up to produce engineered tissue constructs thick enough for in vivo implantation.

Parallel plate bioreactor: Parallel plate bioreactors (PPBs) first used for the expansion of hBMSCs for human haematopoiesis [70-74] consist often of a bottom plate housing a glass slide or porous collagen membrane for cell attachment and growth. When a membrane oxygenator is included, the top plate is sealed with a gas-permeable, but liquid-impermeable membrane. Fresh medium entering spaces between the top and bottom plates flows over cells before exiting. Where a membrane oxygenator is not included, the top plate contains medium inlet and outlet ports [75]. Cells exposed to fluid-flow-induced shear stress has lead in one study to bAChs expressing significantly

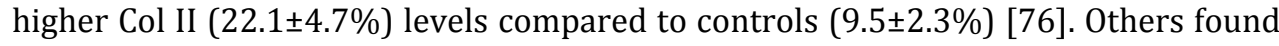
the Young's moduli and ultimate strength significantly increased for bACh culture, i.e. $2.28 \pm 0.19 \mathrm{MPa}$, compared to $1.55 \pm 0.1 \mathrm{MPa}$ for controls [76]. PPBs increase cell-tocell contact, but do not subject cells to adequate mechanical stimuli (besides shear), resulting in lower rates of MSC differentiation and ECM secretion. Also, cartilaginous constructs are too small for relevant clinical treatment.

Non-conventional bioreactors: Optimal balance between self-renewal and differentiation is achieved when culturing in a healthy in vivo environment $[77,78]$. Therefore, closely mimicking the environment should be the central aim in bioreactor design. AC tissue experiences forces 3.9 times the body weight during level walking, and 8.0 times during downhill walking [79]. None of the conventional bioreactors provides cells with mechanical stimulation close to these forces. Lack of mechanical stimulation results in engineered constructs with inferior physicochemical properties [80]. In recent years, researchers began experimenting with novel designs to provide better mechanical stimulation.

Compressive loading appears as two types: confined uniaxial compression in one direction, while deformation in any other direction is prohibited; and unconfined compression, where constructs expand freely perpendicular to the axis of compression [81]. Both confined [82], and unconfined [83], compression improve expression of macromolecules specific to the ECM of AC tissue and prolonged compressive loads decreasing release of newly-synthesized proteoglycans [84]. Since AC tissue in vivo experiences loading between $0.5 \mathrm{MPa}$ to $7.7 \mathrm{MPa}$, and compression amplitudes of more than $13 \%[85,86]$, such bioreactors apply cyclic compression which can increase GAG 
synthesis by $100 \%$ [87]. Others use a frequency of $1 \mathrm{~Hz}$ and either $10 \%[83,88,89]$, or $15 \%[90,91]$, compression to stimulate matrix protein expression and improve compressive properties [92].

Compression is not the only mechanical force experienced by AC in vivo. During joint loading, synovial fluid is retained within the ECM because of negatively charged proteoglycans, resulting in increased hydrostatic pressure (HP) [93]. This varies between standard atmospheric to $10 \mathrm{MPa}$ at a frequency of $1 \mathrm{~Hz}$. BAChs seeded into collagen scaffolds accumulated 3.1 times more GAG when subjected to static HP at 2.8 $\mathrm{MPa}$ [94]. Oscillating HP (OHP) range from 0.1 to $10 \mathrm{MPa}$ at frequencies ranging from 0.01 to $1 \mathrm{~Hz}$ [95-99]. One study found hBMSC pellets subjected to $10 \mathrm{MPa}$ OHP at $1 \mathrm{~Hz}$ for 14 days expressed twice as much Col II and ACAN [100].

In its natural environment, $\mathrm{AC}$ does not experience any of these forces in isolation, but rather undergoes a variety of mechanical stimulations simultaneously. The ideal bioreactor environment is one that applies multiple types of force to developing cultures. Seidel and colleagues [101] combined the forces associated with perfusion with mechanical stimulation (unconfined compression, with a strain amplitude of $5 \%$, and frequency of $0.3 \mathrm{~Hz}$ ), obtaining increased GAG deposition as evidenced by strong safranin-O staining. Wimmer and colleagues [102] developed a bioreactor capable of applying multiaxial loads and shear stress, showing better mRNA expression of oligomeric protein and proteoglycan [103].

However, current engineered constructs still have inferior physicochemical properties compared to endogenous AC [104]. There is room to improve, and considering combined effects of shear stress and OHP had not yet been studied, we designed and built a novel bioreactor that is capable of subjecting cells to these two types of forces, either singularly or in combination, with the aim of better mimicking aspects of the environment present in vivo during tissue development.

\section{Design and development of a unique perfusion/pressurized bioreactor}

Previous non-conventional bioreactors designed to apply mechanical stimulation to AC cultures have a number of potential drawbacks. They typically require the cell constructs be maintained in petri dishes, which are then transferred to the bioreactors where mechanical forces are applied. These type of transfers can increase the risk of bacterial contamination. Another disadvantage is that bioreactors that apply multiple types of mechanical stimulation typically cannot be adjusted to apply each type of mechanical stimulus in isolation, therefore making it difficult to study the effects of combined forces in comparison to individual forces. Moreover, to the best of our knowledge, no bioreactor system is currently available capable of applying both perfusion and OHP at the same time. To overcome these deficiencies, and help further research in the field of AC tissue engineering, we created a new bioreactor system that incorporates the possibility of applying perfusion and OHP simultaneously. The development of this bioreactor can be broken down into three main steps: (1) manufacturing a pressure generator that can create levels of mechanical stimulation similar to those found in the human body, (2) manufacturing a bioreactor device to withstand such high pressures, and (3) automating the system.

Step 1 - Pressure generator: After considering several potential designs for a pressure generator, we ultimately decided on the configuration shown in figure 1. In this design, to increase pressure load on a liquid bioreactor, and create OHP the use of a motor along with a cam was proposed. However, fabricating a liquid tank connected to a motor and cam from scratch is costly. Instead, to create a pressurized liquid a use of compressed air, a master cylinder along with an air cylinder was considered. Among various master and air cylinders tested, the final configuration consists of a pancake tie rod air cylinder (McMaster-CARR, Los Angeles, CA) connected to a Chevrolet half-ton pickup truck master cylinder (O'Reilly Auto Parts, Pullman, WA) as shown in figure 2. Compressed air moves the rod of the air cylinder, which in turn pressurizes hydraulic oil within the master cylinder. 


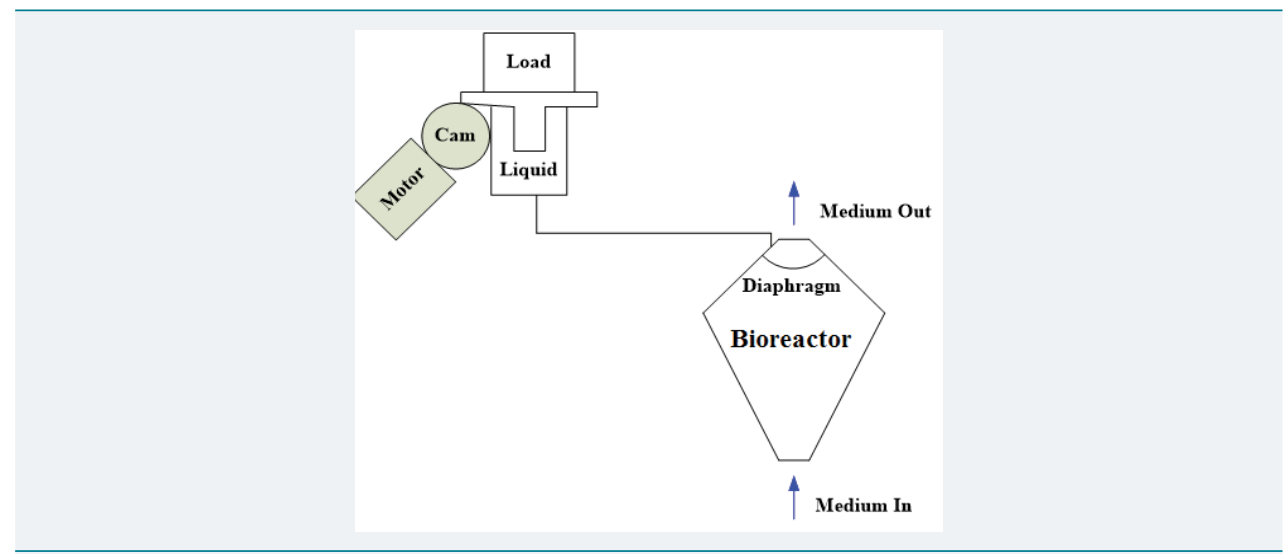

Figure 1: Initial design of the perfusion/pressurized bioreactor system.

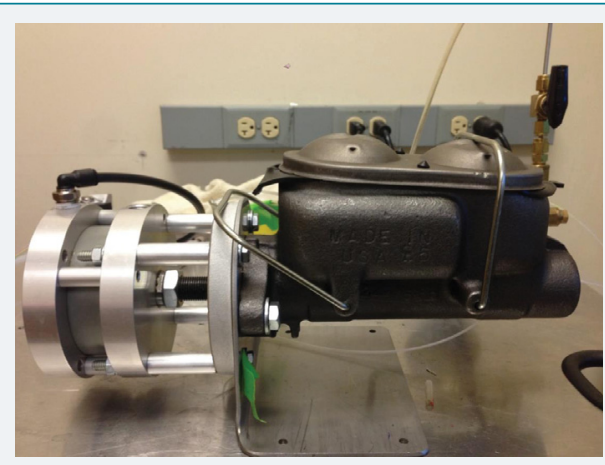

Figure 2: Pressure generator. A pancake tie rod air cylinder (McMaster-CARR, Los Angeles, CA) is connected to a Chevrolet half-ton pickup truck master cylinder (O'Reilly Auto Parts, Pullman, WA).

Step 2 - Bioreactor: After the pressure generator was assembled we built a bioreactor that could withstand high levels of pressure. Two initial designs were evaluated and ultimately rejected, as is shown in figure 3. The Membrane Bioreactor design (Figure 3a) did not work because we could not find a thick enough membrane or stack of membranes that would be capable of withstanding the pressure. The Bellows Bioreactor design (Figure $3 \mathrm{~b}$ ) allowed for a high internal pressure, but due to the bellows slow expansion and contraction rates, this design was also discarded. We ultimately settled on a design that we call the Double-piston Bioreactor (Figure 4). To pressurize liquid medium within the bioreactor, pressurized hydraulic oil from the master cylinder pushes on aluminum pistons connected by screws to polycarbonate pistons at the top of the device. This design allows for quick increases and decreases in pressure.

Step 3 - Automation: To create OHP, a directional-control three-way solenoid valve (Parker, Cleveland, $\mathrm{OH}$ ), in connection with an 8-channel USB relay card, was used (Vellman, Fort Worth, TX). To read pressure in real-time, pressure transducers (DJ Instrument, Billerica, MA) and an NI USB-6008 data-acquisition device (National Instrument, Austin, TX) were incorporated. Microsoft Visual Studio, LabVIEW, and MATLAB software packages were used to control the relay and monitor pressure. The coding implemented in these software applications can be provided upon request.

\section{Application of the newly developed bioreactor system in ACTE}

The capability of the new perfusion/pressurized bioreactor in inducing hADSC chondrogenesis in a scaffold-free mode is described previously [105]. The experimental design for this experiment is summarized in figure 5. Briefly, hADSCs isolated from the lipoaspirate tissue of a 33-year-old female were purchased from Invitrogen-Gibco ${ }^{\circledR}$ (Grand Island, NY) and cultured in an expansion medium (EM) containing high-glucose 


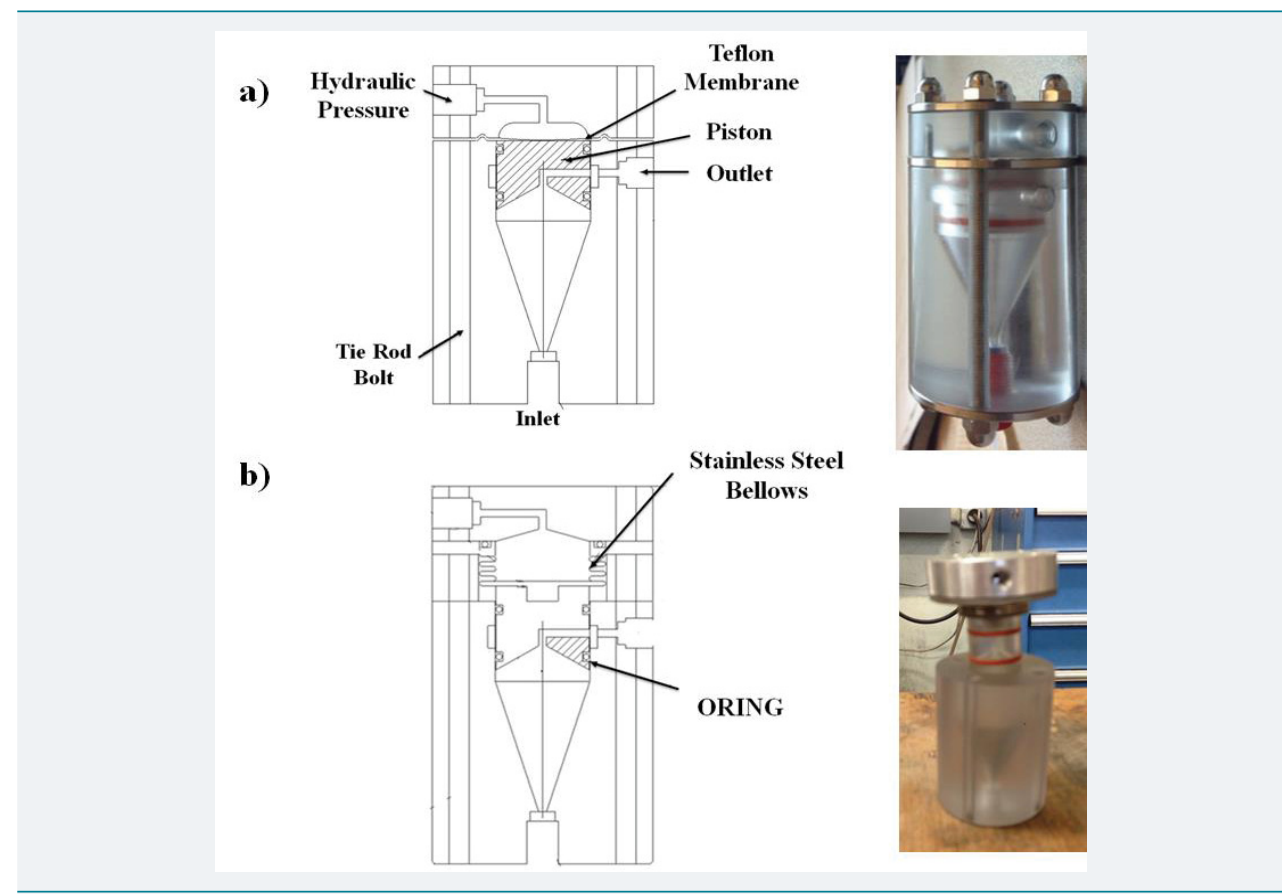

Figure 3: Two potential designs that were ultimately discarded: (a) Membrane Bioreactor, and (b) Bellows Bioreactor.

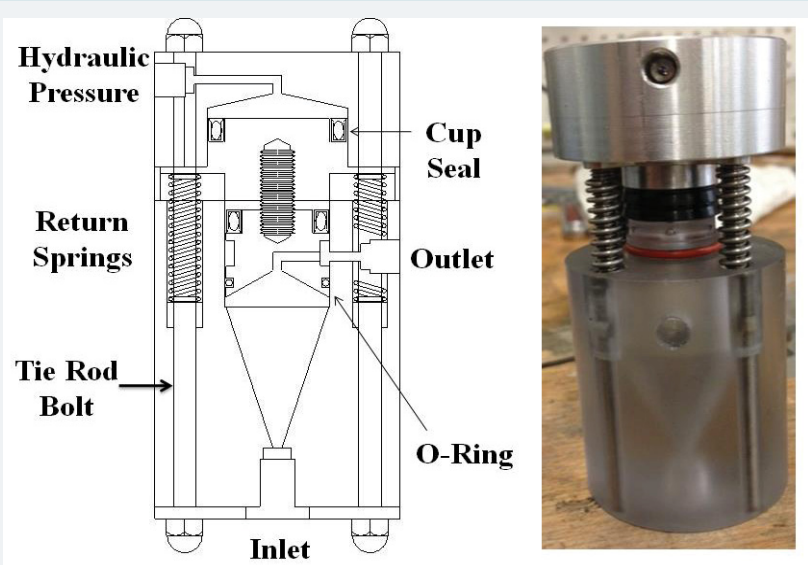

Figure 4: The final Double-piston Bioreactor design (Copyright@American Scientific Publishers [105]).

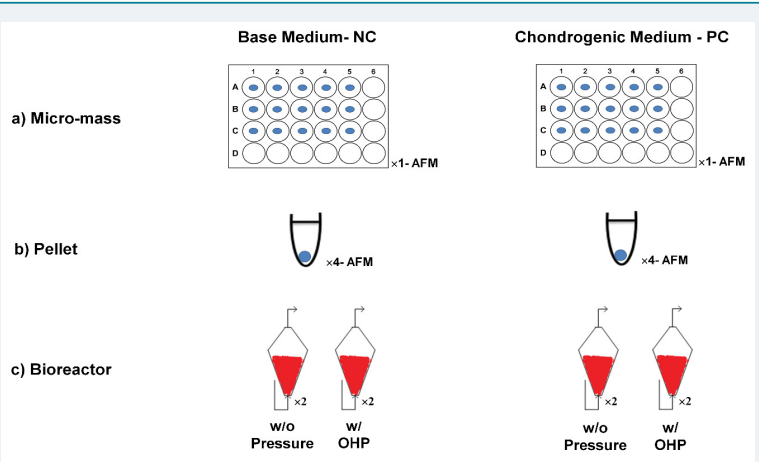

Figure 5: This diagram shows the overall experimental design. NC: negative control - base medium. PC: positive control (PC) - chondrogenic growth factor supplemented medium. AFM: atomic force microscopy. (a) A $10 \mu \mathrm{l}$ droplet of expanded hADSCs at a density of $1.6 \times 10^{7}$ viable cells $/ \mathrm{ml}$ was placed in the center of each of 15 wells in two 24-well culture plates. (b) $5 \times 10^{5}$ hADSCs in $500 \mu$ of EM were centrifuged in each of two microcentrifuge tube sets at $600 \mathrm{~g}$ for 5 minutes, (c) $6 \times 10^{6} \mathrm{hADSCs}$ in $2.5 \mathrm{ml}$ of EM were injected into each reactor with two replicates at each condition, NC with and without oscillating hydrostatic pressure (OHP) and PC with and without OHP. (Figs. $5 a \& b$ reformatted with permission from a previous publication Copyright@American Scientific Publishers [105]; Fig. $5 c$ reused in rearranged form with permission from Springer Nature: Springer-Verlag Berlin Heidelberg, Cell Tissue Res [109] ( ) 2017) 
Dulbecco's Modified Eagle medium (HG-DMEM/F12), supplemented with $10 \%$ fetal bovine serum (FBS), $100 \mathrm{U} / \mathrm{ml}$ penicillin, $100 \mu \mathrm{g} / \mathrm{ml}$ streptomycin (Sigma-Aldrich, St. Louis, MO), and $5 \mu \mathrm{g} / \mathrm{ml}$ Gentamicin. At passage seven, $6{ }^{\prime} 10^{6} \mathrm{hADSCs}$ were injected into each eight $2.5 \mathrm{ml}$, polycarbonate, $3 \mathrm{D}$ funnel-shaped bioreactors under sterile conditions in a biosafety cabinet. Then, the inlet ports were plugged and the bioreactors were mounted on a COBE Spectra ${ }^{\mathrm{TM}}$ Apheresis System (TERUMO BCT, Lakewood, CO) and centrifuged at $500 \mathrm{rpm}$ for 15 minutes. Base or chondrogenic medium supplemented with $20 \mathrm{mM}$ HEPES buffer on a daily basis was continuously pumped for one week into the reactors. The base medium consisted of HG-DMEM/F12 supplemented with $1 \mathrm{mM}$ sodium pyruvate, $2 \mathrm{mM}$ L-glutamine, $5 \mu \mathrm{g} / \mathrm{ml}$ Gentamicin, $1 \%$ Insulin-TransferrinSelenium, $50 \mu \mathrm{M}$ L-proline (Alfa Aesar, Ward Hill, MA), and 1\% penicillin-streptomycin (Sigma-Aldrich). The chondrogenic medium consisted of base medium with $100 \mathrm{nM}$ dexamethasone, $50 \mu \mathrm{g} / \mathrm{ml} \mathrm{L}$-ascorbic acid (both from Sigma-Aldrich), and $10 \mathrm{ng} / \mathrm{ml}$ TGF- $\beta 3$ (PeproTech, Ward Hill, NJ). Medium flow was stopped in reactors for 2 hours a day, corresponding shut off valves closed, and cells exposed to OHP, which was repeated over one week. After pressurization, medium pumping was re-started. The schematic process-flow diagram for the bioreactor system and the typical pressure profile in the bioreactor are shown in figure 5 . The bioreactor samples were compared to micromass and pellet samples (Figure 5). For all micromass, pellet and bioreactor cultures, half the medium was exchanged three times a week. The experiment continued for three weeks in total. The results from this experiment were presented in three published articles [105-107]. In brief, some of the most important findings are that:

I. hADSCs are responsive to the combination of OHP and TGF- $\beta 3$, to the extent that Young's moduli increased to near native values. This result is significantly beyond what has been obtained from the use of either factor alone [105].

II. OHP and TGF- $\beta 3$ are important in improving hADSC chondrogenesis. The path through which this occurs is dependent on $\mathrm{N}$-cadherin expression [106].

III. $\quad \beta 1$-integrin expression is inversely related to Young's moduli of engineered tissue constructs [107].

After the newly developed bioreactor system was shown to be effective for inducing chondrogenesis in a scaffold-free mode, the next logical step was to investigate its potency to induce chondrogenesis when cells are encapsulated in scaffold materials. Scaffolds can provide a three-dimensional environment that closely resembles the physiological ECM of AC tissue, and can thus be used to enhance chondrogenesis and the engineering of AC constructs [108]. To investigate the effectiveness of the newly developed bioreactor in the context of scaffolds, we encapsulated primary bovine AChs in agarose hydrogels [109]. We chose bAChs as they have been widely used in ACTE $[110,111]$, and represent an inexpensive, accessible cell source, which avoids challenges posed by human-derived cells which are limited in availability as they are harvested from patient joint replacements or cadavers. Moreover, agarose was used as the scaffold of choice because it supports growth and chondrogenic differentiation, and reverses dedifferentiation phenomena; that is, dedifferentiated chondrocytes (Chs) re-express the differentiated phenotype after encapsulation in agarose [112]. Furthermore, when encapsulated in agarose, bAChs maintain their phenotype and synthesize Col II and ACAN [113,114]. As shown in previous work [109], reformatted in figure 6 and table 1 to show GAG/Col ratios, results show significant increases in both ECM markers for cells cultured in our bioreactor. The biochemical properties of bovine articular chondrocytes encapsulated in agarose scaffolds for 21-days are compared to cells statically cultured in agarose scaffolds in addition to static micromass and pellet cultures. Our findings are encouraging as we found progressive synergistic enhancements in GAG and Col secretion with a 1.6-fold increase or more with scaffold encapsulation, 5.9-fold when adding $0.02 \mathrm{~Pa}$ of shear stress and a 7.6-fold increase with simultaneous addition of $4 \mathrm{MPa}$ of OHP when compared to micromass samples. 
Moreover, the ratios of GAG/Col are increasing by about two-fold when going from simple scaffold culture to our bioreactor with perfusion and OHP. Investigations of what genes are upregulated because of 3D culture versus those for addition of shear and OHP will be insightful in determining the interplay of various mechanotransduction means with biochemical pathways and differentiation mechanisms. Previously published results also indicate shear stress and OHP induce chondrogenesis and have chondroprotective effects as evidenced by lower mRNA expression of $\beta 1$-integrin, collagen types I and X, and better mechanical properties of the bioreactor samples compared to culture under other conditions (Figure 7).
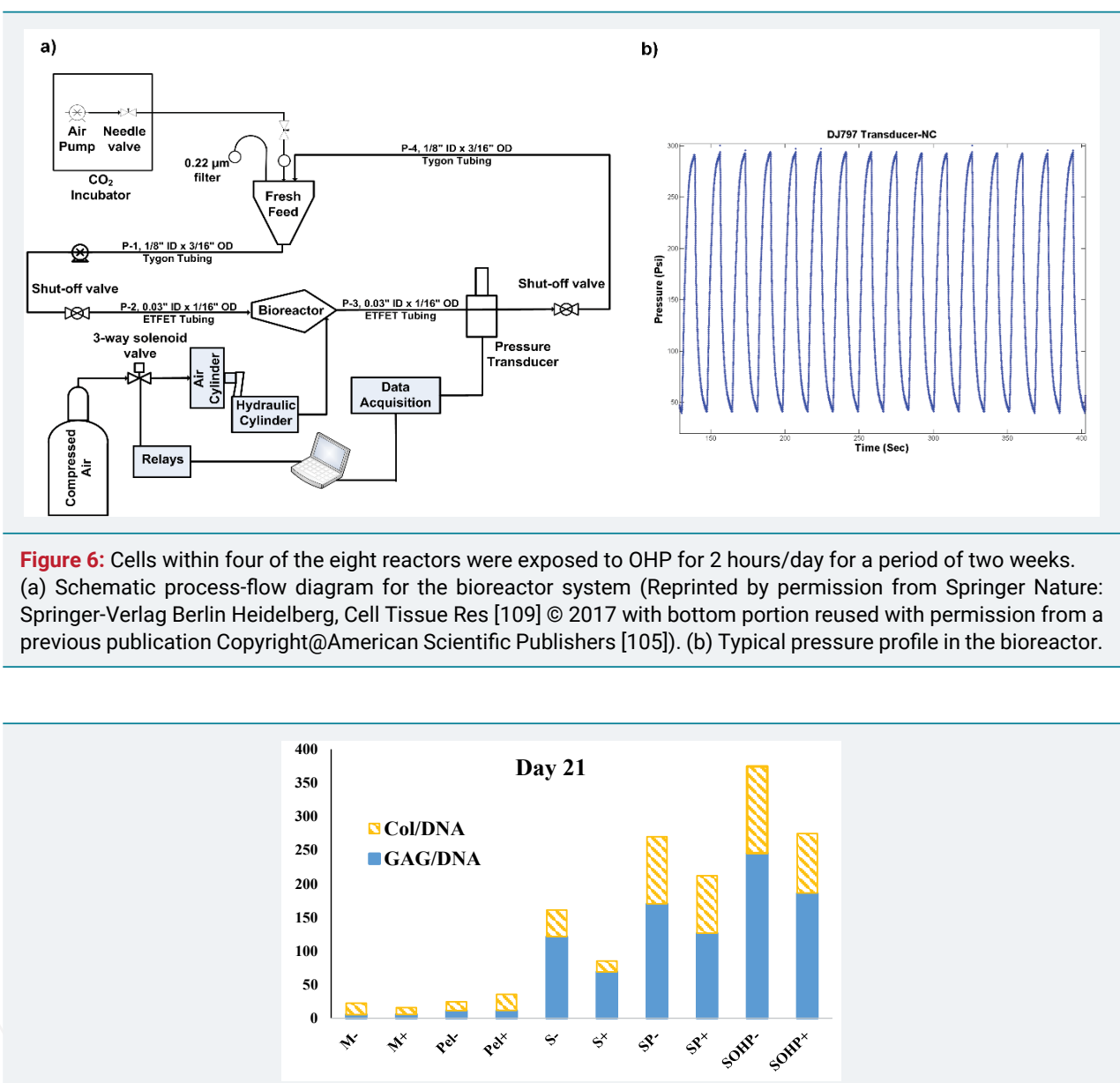

Figure 7: Biochemical properties of engineered tissues. Total GAG and Col content normalized to DNA. M micromass; Pel pellet, S scaffoldstatic; SP scaffold subjected to perfusion; SOHP scaffold subjected to oscillating hydrostatic pressure; - base medium; + chondrogenic medium. This data is reformatted in a ratio form from a previous publication [109].

Table 1: GAG and Col secretion as a function of experimental conditions.

\begin{tabular}{|c|c|c|c|}
\hline Experiment & GAG/DNA & Col/DNA & GAG/Col \\
\hline M- & 17.0 & 5.57 & 3.04 \\
\hline M+ & 10.2 & 5.89 & 1.72 \\
\hline Pel- & 13.1 & 11.5 & 1.14 \\
\hline Pel+ & 24.0 & 11.7 & 2.05 \\
\hline S- & 39.4 & 121 & 0.324 \\
\hline S+ & 16.0 & 69.1 & 0.231 \\
\hline SP- & 99.7 & 170 & 0.586 \\
\hline SP+ & 85.4 & 126 & 0.675 \\
\hline SOHP- & 129 & 254 & 0.506 \\
\hline SOHP+ & 88.4 & 186 & 0.475 \\
\hline
\end{tabular}




\section{Developing of a centrifugal version of the new perfusion/pressurized bioreactor}

To develop further the new perfusion/pressurized bioreactor created in this research, a centrifugal approach was explored. Such a system would allow both scaffoldfree constructs and cell-scaffold constructs to be subjected to higher perfusion rates and more intense shear stresses. This is significant because when flow rate of medium into the original bioreactors was increased to accomplish the same purpose, the cellscaffold constructs started to float. Running in a centrifugal mode subjects the cells within bioreactors to centrifugal, drag, and buoyant forces (Figures 4-7). The drag and buoyant forces cancel the effect of the opposing centrifugal force, thereby immobilizing the cells within the bioreactor [115] (Figure 8). This unique immobilization technique could allow for higher cell densities [115], while simultaneously providing higher levels of shear stress and improving the convective transport of nutrients into, and waste out of, the AC cell cultures [116].

Because of associated potential for running the bioreactors in a centrifugal mode, we moved toward modifying the newly developed perfusion/pressurized system to be used as with a pressurized centrifugal bioreactor (PCBR). In previous work centrifugal bioreactors (CBRs) have been used for monoclonal antibody production [115], and high-density chondrocyte cultures [116]. These studies used a COBE Spectra ${ }^{\mathrm{TM}}$ Apheresis System (TERUMO BCT, Lakewood, CO) as the base for centrifugation, and mounted (at most) two bioreactors on the apheresis rotor. However, because we wanted to compare pressurized vs. non-pressurized samples, and because we wanted to have enough replications, we needed a modified rotor that could support up to four bioreactors. Each of our bioreactors requires one tube for its inlet and one tube for its outlet, so we also needed an assembly that could support 8 tubes in total. For their proper functioning on a centrifuge, these tubes would require some kind of anti-twister mechanism similar to that previously demonstrated by Van Wie and colleagues [117].

One solution to the tube assembly issue would be to use multi-lumen tubing with a total of 8 lumens (one for each tube), which would help to prevent the tubes from becoming twisted and torn while the centrifuge spins. However, because of limited financial resources, we could not design and develop a tube assembly using multilumen tubing. Instead, after months of trial and error, we were eventually able to develop a tube assembly design that allowed supply and removal of medium to all four reactors on the rotor without damage to the tubes (Figure 9). After five days of spinning the newly developed tube assembly no damage to the tubes was observed.

To test the centrifugal version of our bioreactor, we first inoculated 20 million bAChs, at a flow rate of $2 \mathrm{ml} / \mathrm{min}$, while the bioreactors were spinning for one day at 400 RPM. However, the cell density used in this initial test was not sufficient to overcome the Coriolis forces within the rotating bioreactors, and because of this the

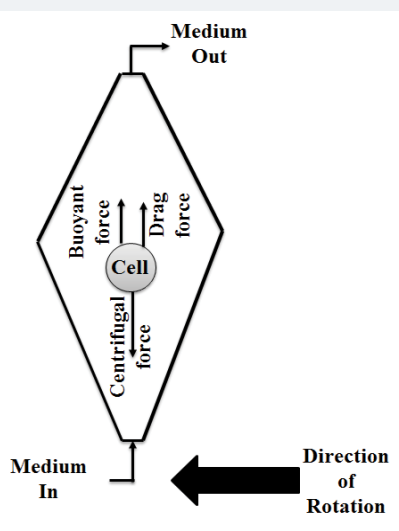

Figure 8: Top view of a centrifugal bioreactor and the forces on a single cell within the bioreactor. 


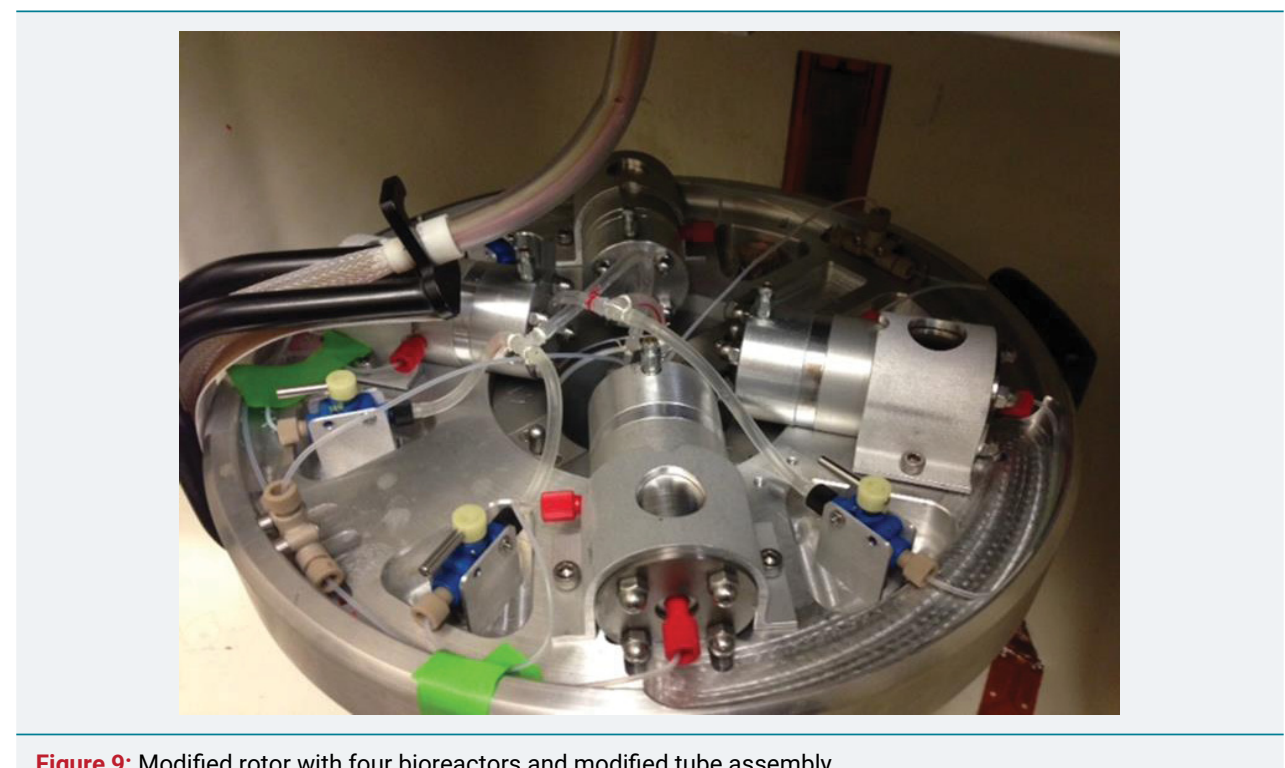

Figure 9: Modified rotor with four bioreactors and modified tube assembly.

cells did not form a pellet but rather adhered to the reactor walls. We adjusted for this in a subsequent test, by inoculating 100 million bAChs at the same flow rate and RPM, and again spinning the bioreactors for one day. This appeared to be successful, so we continued to spin the reactors every day for two hours (one hour in the morning and one hour in the afternoon) at the same flow rate and RPM; during the rest of the time the medium was steadily pumped at $0.1 \mathrm{ml} / \mathrm{min}$. After a week from culture initiation, we began to expose the cells to OHP. The medium perfusion was stopped, corresponding inlet and outlet valves were closed, and the cells were subjected to OHP at $600 \mathrm{psi}$ and 2 Hz. This was done for 4 hours per day, 5 days a week, for 2 weeks. Unfortunately, at the end of the experiment, i.e. after 21 days of culture initiation, the cells had not secreted sufficiently strong ECM, and we were left with constructs that had little integrity. We speculate that the cause of this might be that the bioreactors were not spun for a long enough period of time at the initiation of the culture. When the experiment is repeated in the future, we recommend the bioreactors initially be spun for at least two days so the cells have ample opportunity to form a cohesive pellet. Based on our experience, a high cell population of at least 100 million, is required to run the system in a centrifugal mode. Such a high cell density is not physiologically relevant in ACTE research. Thus, if the bioreactor is run in a centrifugal mode the design should be modified to allow for lower cell density likely by reducing reactor volume.

\section{Future directions}

Micromass and pellet cultures rely on diffusion of TGF- $\beta 3$ into the engineered cells, whereas our bioreactor uses OHP to assist with mass transfer to the core of the cartilage constructs. There is a potential that the OHP approach may increase localized concentration of TGF- $\beta 3$. Theory of incompressible mixtures holds that dynamic loading increases convection of large molecules, such as TGF- $\beta 3$ and may lead to significant concentration increases within the engineered tissue [118]. To test this hypothesis, one could measure TGF- $\beta 3$ concentration within free-swelling versus bioreactor conditions, as a basis for developing theoretical models of concentration gradients in varied construct geometries. Using these concentration gradients, a TGF- $\beta 3$ dose-response experiment with ADSCs could be performed to measure the mechanical properties of 2-D ADSC cultures and/or 3-D hydrogel cultures in pellets of diminishing sizes to assess the impact of mass transfer limitations. Moreover, because our reactor chambers are made of see-through polycarbonate, a stroboscope can be used to conduct studies with dye molecules to display whether or not large molecules such as TGF- $\beta 3$ are indeed entering into the construct at significant concentrations. 
The newly developed bioreactor system can be programmed to apply constant hydrostatic pressures, OHP, differing pressures, and differing frequencies of OHP. Furthermore, different chambers within the bioreactor system can be used side-byside to study scaffold-free cultures versus those with scaffolds made up of differing gel compositions. As a result we now have the ability to test a large number of research hypotheses and answer critical questions about the nature of the constructs formed as well as underlying mechanisms governing chondrogenesis. The technology can easily be adjusted for other applications to apply static or cyclic confined or unconfined pressures. In the new design, the second piston would be a long cylinder that directly puts pressure on cell-constructs. The strain to which cell-constructs are subjected can be measured using a strain gauge connected to the same data acquisition system. Having bioreactors that could subject cell-constructs to various types of mechanical stimuli enables not only comprehensive studies comparing the effects of different mechanical stimuli but also determination of the best combination of mechanical stimuli to induce chondrogenesis and the optimal magnitude of these stimuli.

Current ACTE strategies cannot yet fabricate new tissue that is indistinguishable from endogenous $\mathrm{AC}$ with respect to its composition, and architectural and mechanical properties. Part of the reason is the limitations of current scaffolding techniques. As shown in figure 10, natural AC architecture is divided into four zones. The superficial zone, which is adjacent to the joint cavity, is characterized by flat cells and collagen fibrils oriented parallel to the surface. The intermediate zone is characterized by round cells and collagen fibrils randomly oriented. The deep zone is characterized by round cells organized into distinct vertical columns where collagen fibrils are oriented perpendicularly to the articular surface. The calcified zone, adjacent to the subchondral bone, is characterized by radially aligned collagen fibrils and few chondrocytes [119]. This complex architecture of AC cannot be mimicked simply by encapsulating cells in hydrogels and/or seeding cells onto pre-formed polymeric scaffolds. Such methods do not allow for precise cell-suspension and orientation at the targeted location [120].

Layer-by-layer bioprinting is a new technology with exciting prospects for improving the functionality of tissue engineering scaffolds, by allowing the precise placement of cells, biomaterials, and bioactive cues in a 3D space in a way that can better mimic the complexities of native tissue [121]. Future studies are recommended to tackle challenges associated with 3D bioprinting in the realm of ACTE. One important issue is improving the design of the "bio-ink," as current bio-inks have major limitations such as a loss of their mechanical properties during in vitro culturing [122], or untenable variations between different batches of bio-ink [123]. Studies to investigate the response of 3D-printed constructs to mechanical stimuli would also be of great interest.

Our results support the view that a synergistic outlook focused on integrating all four components of AC tissue engineering (cells, exogenous biochemical factors, bioreactors, and scaffolds) into a cohesive method is the most effective way to obtain superior results. Following the conclusions of the work describe here, we hypothesize that enhanced

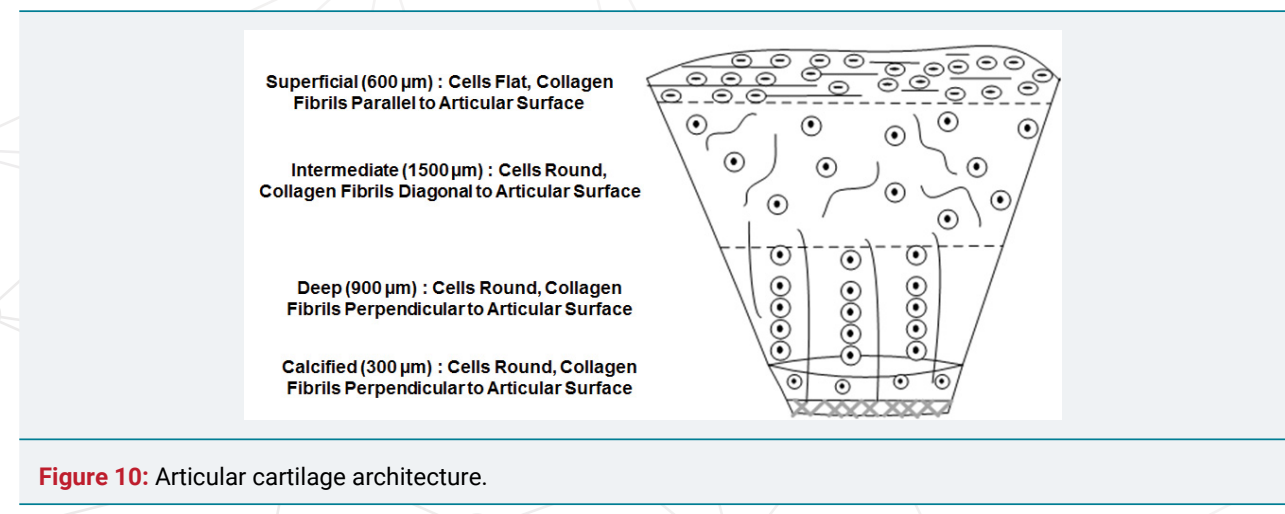


differentiation of hMSCs may be achieved by co-culturing these cells with human articular chondrocytes (hAChs), bioprinting the cells in multilayer 3D hydrogels at varied ratios, and subjecting them simultaneously to various mechanical and bio-active stimuli.

MSCs and AChs co-exist in vivo, and when co-cultured in vitro, both cell types interact mutually in that signaling molecules secreted by AChs induce MSC chondrogenesis and suppress their hypertrophy and the signaling molecules secreted by MSCs support ACh viability and proliferation [124]. Since our system has proven effective in inducing chondrogenesis of each cell type alone, we do not foresee any problems in utilizing the system to study co-culture environment. MSCs derived from either adipose tissues or bone-marrow can be co-cultured with either AChs or nasal chondrocytes in scaffoldfree mode or encapsulated in scaffolds and subjected to mechanical stimuli in our bioreactors. We hypothesize that enhanced differentiation of MSCs may be achieved by co-culturing these cells with chondrocytes, bioprinting the cells in multilayer 3D hydrogels at varied ratios, and subjecting them simultaneously to various mechanical and bio-active stimuli. Using the system described, co-cultured cells can be subjected to OHP with varying magnitudes or with a small modification, the effects of different types of mechanical stimuli on co-cultured cells can be studied. Future studies are recommended to this hypothesis.

The application of our newly developed bioreactor system goes beyond ACTE. For example, our perfusion bioreactor without any modification requirement can be used for bone tissue engineering. In the United States alone, there are over six million bone injuries and over one million bone grafting procedures annually. Bone tissue engineering represents a promising approach to currently available bone grafting procedures including autograft and allograft. Autograft procedures have detrimental effects on the healthy donor cites and allograft procedures are associated with the risk of immune response in recipients. Bone tissue engineering approaches involve seeding a cell source on a scaffold and implanting a cell-seeded scaffold into the site of injury after inducing osteogenesis. Perfusion-induced shear stress is among the induction factors that improve osteogenic signal expression of MSCs [46,125]. Perfusion-induced shear stress with magnitudes as little as $0.001 \mathrm{~Pa}$ [126], to as high as $2 \mathrm{~Pa}$ [127], is shown to improve osteogenesis as evidenced by enhancement in expression of bone sialoprotein and osteopontin in rat BMSCs [126], and increases in calcium deposition by human osteoblasts [127]. Inasmuch as cell-scaffold constructs can be subjected to shear stress in our perfusion bioreactor, one may use different chambers to study osteogenesis under the influence of differing magnitudes of shear stress. If run in a centrifugal mode, this can be achieved by pumping medium with different flow rates to each of four bioreactors on the same rotor while experiencing the same centrifugal force. Moreover, one can use different chambers to compare the effects of commonly used osteoinductive factors such as vascular endothelial growth factor, or bone morphogenic protein types 2 and 7 [128], while keeping the shear stress constant.

There is a continuing need for novel bioreactors that support high cell population density and high volumetric productivity, while maintaining product quality, as demanded for expansion of specific mammalian cells and cellular secreted products, such as therapeutic and diagnostic mAbs, and recombinant proteins. In 2013, global sales revenue for all monoclonal antibody products was nearly $\$ 75$ billion, representing approximately half of the total sales of all biopharmaceutical products [129]. High cell densities of $10^{8}$ cells $/ \mathrm{ml}$ [115], and high mAb productivity of $40 \mu \mathrm{g} / \mathrm{ml}$ have been achieved in an $11.4 \mathrm{ml}$ bioreactor in a centrifugal mode [130]. Even though the cell density achieved in the CBR is similar to that of HFBs and packed bed bioreactors (PBRs), the CBR use is preferable since the typical problems associated with HFBs and PBRs such as membrane fouling and diffusional limitations are not with "in CBRs. With the newly developed tube assembly and housing of four bioreactors on one rotor, the productivity would increase to $600 \mu \mathrm{g} / \mathrm{ml}$. Application of CBRs can be extended to any other areas where high cell population densities are needed. For example, CBRs could be used to produce high concentrations of cytotoxic CD8 T-lymphocytes (CTLs) allowing researchers to assess use in personalized cell-based therapies. 


\section{Conclusion}

Existing bioreactor systems are not yet fully capable of engineering cohesive, organized tissue constructs with biochemical and biophysical properties similar to native AC. Simultaneous combination of perfusion and OHP at the same time is a topic that could not be explored with previous bioreactor designs. To respond to this need and help advance the field, we designed and built a new computer-controlled perfusion/ pressurized bioreactor system. Our perfusion/pressurized bioreactor is capable of inducing chondrogenesis and opens new opportunities for researching the mechanisms associated with AC tissue growth. It allows mechanical stimulation of the tissue cultures to be performed without the requirement of transferring them to a separate chamber, thus reducing the potential risk of contamination.

Using this new bioreactor system, we induced hADSC chondrogenesis and obtained tissue constructs with a Young's moduli close to native values. The new bioreactor can also be used to test a wide variety of additional hypotheses in future studies. For example, as discussed, co-culturing hADSCs with hAChs is a promising technique that may be used in the future to engineer tissue constructs in vitro for in vivo implantation. Future studies could employ this system for investigating the effects of perfusion and OHP on co-culture environments.

\section{Acknowledgement}

Financial support from NSF EAGER grant CBET-1212573 and GOALI CBET1606226 as well as salary support for Prof. Van Wie from USDA NIFA Hatch Project \#WNP00807 is acknowledged. The authors acknowledge Regeneron Pharmaceuticals, Inc. for ADSCs, TGF- $\beta$, medium and collagenase supplies, Potlatch Pack for supply of bovine carpal joints, undergraduate students Ashley Davie and Tyler Cheung for their help in isolating bAChs, Gary Held and Miles Pepper from the WSU Voiland College of Engineering and Architecture Machine Shop for assistance in manufacture and assembly of the bioreactor system. Also, acknowledged are Dr. Chrystal Quisenberry, Sam Uzoechi, and Profs. Nehal Abu-Lail and Arda Gozen for helpful discussions on 3D printed and multi-layered chondrocyte constructs. Quisenberry and Abu-Lail are also authors in key publications summarized in the results section to demonstrate efficacy of the bioreactor concept.

\section{References}

1. Fecek C, Yao D, Kaçorri A, Vasquez A, lqbal S, et al. Chondrogenic derivatives of embryonic stem cells seeded into $3 \mathrm{D}$ polycaprolactone scaffolds generated cartilage tissue in vivo. Tissue Eng Part A. $2008 ; 14$ : 1403-1413. Ref.: https://tinyurl.com/y7mc2myh

2. Chang Q, Cui WD, Fan WM. Co-culture of chondrocytes and bone marrow mesenchymal stem cells in vitro enhances the expression of cartilaginous extracellular matrix components. Braz $\mathrm{J}$ Med Biol Res. 2011; 44: 303-310. Ref.: https://tinyurl.com/yakcnrf8

3. Mobasheri A, Vannucci SJ, Bondy CA, Carter SD, Innes JF, et al. Glucose transport and metabolism in chondrocytes: a key to understanding chondrogenesis, skeletal development and cartilage degradation in osteoarthritis. Histol Histopathol. 2002; 17: 1239-67. Ref.: https://tinyurl.com/y7hf92yw

4. Olee T, Grogan SP, Lotz MK, Colwell CW Jr, D'Lima DD, et al. Repair of Cartilage Defects in Arthritic Tissue with Differentiated Human Embryonic Stem Cells. Tissue Eng Part A. 2013; 19: 19.

5. Mauck RL, Soltz MA, Wang CCB, Wong DD, Chao PHG, et al. Functional tissue engineering of articular cartilage through dynamic loading of chondrocyte-seeded agarose gels. Journal of Biomechanical Engineering-Transactions of the ASME. 2000; 122: 252-260. Ref.: https://tinyurl.com/y7o5ajwz

6. von der Mark K, Gauss V, von der mark H, müller P. Relationship between cell shape and type of collagen synthesised as chondrocytes lose their cartilage phenotype in culture. Nature. 1977; 267: 531-532. Ref.: https://tinyurl.com/ybtqrffo

7. Schnabel M, Marlovits S, Eckhoff G, Fichtel I, Gotzen L, et al. Dedifferentiation-associated changes in morphology and gene expression in primary human articular chondrocytes in cell culture. Osteoarthritis Cartilage. 2002; 10: 62-70. Ref.: https://tinyurl.com/yd4e8j3m 
8. Kim HJ, Im GI. Chondrogenic differentiation of adipose tissue-derived mesenchymal stem cells: greater doses of growth factor are necessary. J Orthop Res. 2009; 27: 612-619. Ref.: https://tinyurl.com/y84pyhee

9. Zhang L, Su P, Xu C, Yang J, Yu W, et al. Chondrogenic differentiation of human mesenchymal stem cells: a comparison between micromass and pellet culture systems. Biotechnology Lett. 2010; 32 : 1339-1346. Ref.: https://tinyurl.com/yaoctvw9

10. Puetzer JL, Petitte JN, Loboa EG. Comparative review of growth factors for induction of threedimensional in vitro chondrogenesis in human mesenchymal stem cells isolated from bone marrow and adipose tissue. Tissue Eng Part B Rev. 2010; 16: 435-444. Ref.: https://tinyurl.com/y8drpuln

11. Zhang L, Su P, Xu C, Yang J, Yu W, et al. Chondrogenic differentiation of human mesenchymal stem cells: a comparison between micromass and pellet culture systems. Biotechnology Lett. 2010; 32: 1339-1346. Ref.: https://tinyurl.com/yaoctvw9

12. Godara P, McFarland CD, Nordon RE. Design of bioreactors for mesenchymal stem cell tissue engineering. J Chem Technol Biotechnol. 2008; 83: 408-420. Ref.: https://tinyurl.com/y7ungm2f

13. Bancroft GN, Sikavitsas VI, Mikos AG. Design of a flow perfusion bioreactor system for bone tissueengineering applications. Tissue Eng. 2003; 9: 549-554. Ref.: https://tinyurl.com/y6uqnsq8

14. Xu F, Xu L, Wang Q, Zhou Y, Ye Z, et al. A three-dimensional dynamic coculture system enabling facile cell separation for chondrogenesis of mesenchymal stem cells. Biochemical Engineering Journal. 2015; 103: 68-76. Ref.: https://tinyurl.com/y6uqnsq8

15. Vunjak-Novakovic G, Freed LE, Biron RJ, Langer R. Effects of mixing on the composition and morphology of tissue-engineered cartilage. AlChE Journal. 1996; 42: 850-860. Ref.: https://tinyurl.com/y6vwvlj7

16. Song K, Li L, Li W, Zhu Y, Jiao Z, et al. Three-dimensional dynamic fabrication of engineered cartilage based on chitosan/gelatin hybrid hydrogel scaffold in a spinner flask with a special designed steel frame. Mater Sci Eng C Mater Biol Appl. 2015; 55: 384-392. Ref.: https://tinyurl.com/ycne5b3f

17. Janjanin S, Li WJ, Morgan MT, Shanti RM, Tuan RS. Mold-Shaped, Nanofiber Scaffold-Based Cartilage Engineering Using Human Mesenchymal Stem Cells and Bioreactor. J Surg Res. 2008; 149: 47-56. Ref.: https://tinyurl.com/yd3d3zt4

18. Mygind T, Stiehler M, Baatrup A, Li H, Zou X, Flyvbjerg A. Mesenchymal stem cell ingrowth and differentiation on coralline hydroxyapatite scaffolds. Biomaterials. 2007; 28: 1036-1047. Ref.: https://tinyurl.com/yaclvsol

19. Stiehler M, Bünger $C$, Baatrup $A$, Lind $M$, Kassem M, et al. Effect of dynamic 3-D culture on proliferation, distribution, and osteogenic differentiation of human mesenchymal stem cells. J Biomed Mater Res A. 2009; 89: 96-107. Ref.: https://tinyurl.com/ya46zzp2

20. Chen HC, Hu YC. Bioreactors for tissue engineering. Biotechnol Lett. 2006; 28: 1415-1423. Ref.: https://tinyurl.com/y8v4dq4t

21. Freed LE, Vunjak-Novakovic G. Tissue Enginnering Bioreactors, In: Principles of Tissue Engineering, Lanza R, Langer R, and Vacanti J, Editors. Academic Press: San Diego. 2000; 143-156.

22. Meinel L, Karageorgiou V, Fajardo R, Snyder B, Shinde-Patil V, et al. Bone tissue engineering using human mesenchymal stem cells: effects of scaffold material and medium flow. Ann Biomed Eng. 2004; 32: 112-122. Ref.: https://tinyurl.com/y8yeocea

23. Vunjak-Novakovic G, Obradovic B, Martin I, Bursac PM, Langer R, et al. Dynamic cell seeding of polymer scaffolds for cartilage tissue engineering. Biotechnol Prog. 1998; 14: 193-202. Ref.: https://tinyurl.com/y95zpo8q

24. Schwarz RP, Goodwin TJ, Wolf DA. Cell culture for three-dimensional modeling in rotating-wall vessels: an application of simulated microgravity. J Tissue Cult Methods. 1992; 14: 51-57. Ref.: https://tinyurl.com/ycjs4ylu

25. Schwarz RP, Wolf DA. Rotating bio-reactor cell culture apparatus. U. S. Patent, NASA. 4,988, 623: 1-14. Ref.: https://goo.gl/nLT617

26. Wolf DA, Sam GF, Schwarz RP. High aspect reactor vessel and method of use. U. S. Patent, NASA 5,153,131: 1-14. Ref.: https://goo.gl/Xb5Jtv

27. Granet C, Laroche N, Vico L, Alexandre C, Lafage-Proust MH. Rotating-wall vessels, promising bioreactors for osteoblastic cell culture: comparison with other 3D conditions. Med Biol Eng Comput. 1998; 36: 513-519. Ref.: https://tinyurl.com/yd2lq5mq 
28. Song K, Yang Z, Liu T, Zhi W, Li X, et al. Fabrication and detection of tissue-engineered bones with bio-derived scaffolds in a rotating bioreactor. Biotechnol Appl Biochem. 2006; 45: 65-74. Ref.: https://tinyurl.com/yd3kkjbt

29. Langer R, Martin I, Pellis NR, Vunjak-Novakovic G. Tissue engineering of cartilage in space. Proc Natl Acad Sci USA. 1997; 94: 13885-13890. Ref.: https://tinyurl.com/ybxycsp6

30. Ohyabu Y, Kida N, Kojima H, Taguchi T, Tanaka J, et al. Cartilaginous tissue formation from bone marrow cells using rotating wall vessel (RWV) bioreactor. Biotechnol Bioeng. 2006; 95: 1003-1008. Ref.: https://tinyurl.com/ybvxgrn7

31. Sakai S, Mishima H, Ishii T, Akaogi H, Yoshioka T, et al. Rotating three-dimensional dynamic culture of adult human bone marrow-derived cells for tissue engineering of hyaline cartilage. J Orthop Res. 2009; 27: 517-521. Ref.: https://tinyurl.com/y7ekt3td

32. Yoshioka T, Mishima H, Ohyabu Y, Sakai S, Akaogi H, et al. Repair of large osteochondral defects with allogeneic cartilaginous aggregates formed from bone marrow-derived cells using RWV bioreactor. J Orthop Res. 2007; 25: 1291-1298. Ref.: https://tinyurl.com/y99nrbkg

33. Marolt $D$, Augst A, Freeda LE, Veparic $C$, Fajardo $R$, et al. Bone and cartilage tissue constructs grown using human bone marrow stromal cells, silk scaffolds and rotating bioreactors. Biomaterials. 2006; 27: 6138-6149. Ref.: https://tinyurl.com/ybpugwzf

34. Chen HC, Sung LY, Lo WH, Chuang CK, Wang YH, et al. Combination of baculovirus-expressed BMP-2 and rotating-shaft bioreactor culture synergistically enhances cartilage formation. Gene Ther, 2008. 15: 309-317. Ref.: https://tinyurl.com/y7p8mzdm

35. Lu CH, Lin KJ, Chiu HY, Chen CY, Yen TC, et al. Improved chondrogenesis and engineered cartilage formation from TGF-beta3-expressing adipose-derived stem cells cultured in the rotating-shaft bioreactor. Tissue Eng Part A. 2012; 18: 2114-2124. Ref.: https://tinyurl.com/y9b8x7yf

36. Chen HC, Lee HP, Sung ML, Liao CJ, Hu YC. A novel rotating-shaft bioreactor for two-phase cultivation of tissue-engineered cartilage. Biotechnol Prog. 2004; 20: 1802-1809. Ref.: https://tinyurl.com/ybouj39j

37. Singh V. Disposable bioreactor for cell culture using wave-induced agitation. Cytotechnology. 1999; 30: 149-158. Ref.: https://tinyurl.com/ydfkh3on

38. Kadarusman J, Bhatia R, McLaughlin J, Lin WR. Growing cholesterol-dependent NSO myeloma cell line in the wave bioreactor system: overcoming cholesterol-polymer interaction by using pretreated polymer or inert fluorinated ethylene propylene. Biotechnol Prog. 2005; 21: 1341-1346. Ref.: https://tinyurl.com/y86x8vn7

39. Zhang $\mathrm{Y}$, Meng $\mathrm{H}$, Hou S. Method for preparing mesenchymal stem cells in scale by use of bioreactor. Union Stem Cell \& Gene Engineering Co., Ltd., Peop Rep China. 2011; 6.

40. Mizuno S, Allemann F, Glowacki J. Effects of medium perfusion on matrix production by bovine chondrocytes in three-dimensional collagen sponges. J Biomed Mater Res. 2001; 56: 368-375. Ref.: https://tinyurl.com/y988sed3

41. Alves da Silva ML, Martins A, Costa-Pinto AR, Correlo VM, Sol P. Chondrogenic differentiation of human bone marrow mesenchymal stem cells in chitosan-based scaffolds using a flow-perfusion bioreactor. J Tissue Eng Regen Med. 2011; 5: 722-732. Ref.: https://tinyurl.com/y9qg3jjn

42. Davisson T, Sah RL, Ratcliffe A. Perfusion increases cell content and matrix synthesis in chondrocyte three-dimensional cultures. Tissue Eng. 2002; 8: 807-816. Ref.: https://tinyurl.com/yczhjxrm

43. Pazzano D, Mercier KA, Moran JM, Fong SS, DiBiasio DD. Comparison of chondrogensis in static and perfused bioreactor culture. Biotechnol Prog. 2000; 16: 893-896. Ref.: https://tinyurl.com/ydbq2kvcb

44. Santoro R, Olivares AL, Brans G, Wirz D, Longinotti C, et al. Bioreactor based engineering of largescale human cartilage grafts for joint resurfacing. Biomaterials. 2010; 31: 8946-8952. Ref.: https://tinyurl.com/yc8jwgtv

45. Gomes ME, Sikavitsas VI, Behravesh E, Reis RL, Mikos AG. Effect of flow perfusion on the osteogenic differentiation of bone marrow stromal cells cultured on starch-based three-dimensional scaffolds. J Biomed Mater Res A. 2003; 67: 87-95. Ref.: https://tinyurl.com/ycl8ak48

46. Yeatts $A B$, Fisher JP. Bone tissue engineering bioreactors: dynamic culture and the influence of shear stress. Bone. 2011; 48: 171-181. Ref.: https://tinyurl.com/ybrgtq6x

47. Bancroft GN, Sikavitsas VI, van den Dolder J, Sheffield TL, Ambrose CG, et al. Fluid flow increases mineralized matrix deposition in $3 \mathrm{D}$ perfusion culture of marrow stromal osteoblasts in a dosedependent manner. Proc Natl Acad Sci USA. 2002; 99: 12600-12605. Ref.: https://tinyurl.com/yc6dftpf 
48. Shahin K, Doran PM. Strategies for enhancing the accumulation and retention of extracellular matrix in tissue-engineered cartilage cultured in bioreactors. Plos One. 2011; 6: 15. Ref.: https://tinyurl.com/ydz2du7w

49. Yeatts AB, Fisher JP. Tubular Perfusion System for the Long-Term Dynamic Culture of Human Mesenchymal Stem Cells. Tissue Eng Part C. 2011; 17: 337-348. Ref.: https://tinyurl.com/y8arskg6

50. Coates EE, Riggin CN, Fisher JP. Photocrosslinked alginate with hyaluronic acid hydrogels as vehicles for mesenchymal stem cell encapsulation and chondrogenesis. J Biomed Mater Res A. 2013; 101: 1962-1970. Ref.: https://tinyurl.com/ycv6bngg

51. Guo T, Yu L, Lim CG, Goodley AS, Xiao X, et al. Effect of Dynamic Culture and Periodic Compression on Human Mesenchymal Stem Cell Proliferation and Chondrogenesis. Ann Biomed Eng. 2016; 44: 2103-2113. Ref.: https://tinyurl.com/y7dyynrb

52. Knazek RA, Wu YW, Aebersold PM, Rosenberg SA. Culture of human tumor infiltrating lymphocytes in hollow fiber bioreactors. J Immunol Methods. 1990; 127: 29-37. Ref.: https://tinyurl.com/y96ddz8g

53. Nordon RE, Schindhelm K. Design of hollow fiber modules for uniform shear elution affinity cell separation. Artif Organs. 1997; 21: 107-115. Ref.: https://tinyurl.com/yam24fuw

54. Abu-Absi SF, Seth G, Narayanan RA, Groehler K, Lai P, et al. Characterization of a hollow fiber bioartificial liver device. Artif Organs. 2005; 29: 419-422. Ref.: https://tinyurl.com/yd76fv74

55. Meng Q, Zhang G, Wu D. Hepatocyte culture in bioartificial livers with different membrane characteristics. Biotechnology Lett. 2004; 26: 1407-1412. Ref.: https://tinyurl.com/yafmn2zp

56. Malone CC, Schiltz PM, Mackintosh AD, Beutel LD, Heinemann FS, et al. Characterization of human tumor-infiltrating lymphocytes expanded in hollow-fiber bioreactors for immunotherapy of cancer. Cancer Biother Radiopharm. 2001; 16: 381-390. Ref.: https://tinyurl.com/ya29jwnk

57. Potter K, Butler JJ, Adams C, Fishbein KW, McFarland EW, et al. Cartilage formation in a hollow fiber bioreactor studied by proton magnetic resonance microscopy. Matrix Biol. 1998; 17: 513-523. Ref.: https://tinyurl.com/ycbkyrzq

58. Potter K, Butler JJ, Horton WE, Spencer RG. Response of engineered cartilage tissue to biochemical agents as studied by proton magnetic resonance microscopy. Arthritis Rheum. 2000; 43: 1580-1590. Ref.: https://tinyurl.com/y757q7vw

59. Ellis SJ, Velayutham M, Velan SS, Petersen EF, Zweier JL, et al. EPR oxygen mapping (EPSOM) of engineered cartilage grown in a hollow-fiber bioreactor. Magn Reson Med. 2001; 46: 819-826. Ref.: https://tinyurl.com/y7oab3az

60. Potter K, Kidder LH, Levin IW, Lewis EN, Spencer RG. Imaging of collagen and proteoglycan in cartilage sections using Fourier transform infrared spectral imaging. Arthritis Rheum. 2001; 44: 846855. Ref.: https://tinyurl.com/y8krneov

61. Kim M, Bi X, Horton WE, Spencer RG, Camacho NP, et al. Fourier transform infrared imaging spectroscopic analysis of tissue engineered cartilage: histologic and biochemical correlations. J Biomed Opt. 2005; 10: 031105. Ref.: https://tinyurl.com/yaqanqqq

62. Liu, T, Li, X, Cui, Z, Zhu, L. Method for amplification of bone marrow-derived mesenchymal stem cells under dynamic three-dimensional conditions. Dalian University of Technology, Peop Rep China. $2007 ; 13$.

63. Antwiler GD, Peters RL, Windmiller DA. Method of reseeding adherent cells grown in a hollow fiber bioreactor system. CaridianBCT, Inc., USA. Cont.-in-part of U.S. Ser. No. 42,763. 2011; 9.

64. Antwiler GD. Culture of mesenchymal stem cells including seeding on a hollow-fiber membrane. Gambro BCT, Inc., USA. 2007; 8.

65. De Napoli IE, Scaglione S, Giannoni P, Quarto R, Catapano G. Mesenchymal stem cell culture in convection-enhanced hollow fibre membrane bioreactors for bone tissue engineering. J Membr Sci. 2011; 379: 341-352. Ref.: https://tinyurl.com/yarx8s82

66. Li X, Liu T, Song K, Ma X, Cui Z. Culture and expansion of mesenchymal stem cells in air-lift loop hollow fiber membrane bioreactor. Gaoxiao Huaxue Gongcheng Xuebao. 2008; 22: 985-991. Ref.: https://tinyurl.com/y7z2p5qx

67. Li X, Liu T, Song K, Ma X, Cui Z. Hypoxic culture and expansion of mesenchymal stem cells in airlift loop hollow fiber membrane bioreactor. Cell Res. 2008; 18: S169. Ref.: https://tinyurl.com/ycyqxy56

68. Nold P, Brendel C, Neubauer A, Bein G, Hackstein H. Good manufacturing practice-compliant animal-free expansion of human bone marrow derived mesenchymal stroma cells in a closed hollow-fiber-based bioreactor. Biochem Biophys Res Commun. 2013; 430: 325-330. Ref.: https://tinyurl.com/yb2sylz2 
69. Chresand TJ, Gillies RJ, Dale BE. Optimum fiber spacing in a hollow fiber bioreactor. Biotechnol Bioeng. 1988; 32: 983-992. Ref.: https://tinyurl.com/y7yrv6ml

70. Wang TY, Wu JH. A continuous perfusion bioreactor for long-term bone marrow culture. Ann $\mathrm{N} \mathrm{Y}$ Acad Sci. 1992; 665: 274-284. Ref.: https://tinyurl.com/ycouyqbb

71. Koller MR, Bender JG, Miller WM, Papoutsakis ET. Expansion of primitive human hematopoietic progenitors in a perfusion bioreactor system with IL-3, IL-6, and stem cell factor. Biotechnology. 1993; 11: 358-363. Ref.: https://tinyurl.com/y8u42mzv

72. Peng CA, Palsson BO. Cell growth and differentiation on feeder layers is predicted to be influenced by bioreactor geometry. Biotechnol Bioeng. 1996; 50: 479-492. Ref.: https://tinyurl.com/y8u42mzv

73. Palsson BO, Paek SH, Schwartz RM, Palsson M, Lee GM, et al. Expansion of human bone marrow progenitor cells in a high cell density continuous perfusion system. Biotechnology. 1993; 11: 368372. Ref.: https://tinyurl.com/y8oy8h9g

74. Koller MR, Emerson SG, Palsson BO. Large-scale expansion of human stem and progenitor cells from bone marrow mononuclear cells in continuous perfusion cultures. Blood. 1993; 82: 378-384. Ref.: https://tinyurl.com/y8kakstw

75. Roy P, Harihara B, Arno Tilles W, Martin Yarmush L, Mehmet Toner. Analysis of oxygen transport to hepatocytes in a flat-plate microchannel bioreactor. Ann Biomed Eng, 2001. 29: 947-955. Ref.: https://tinyurl.com/y79xs2y4

76. Gemmiti CV, Guldberg RE. Fluid flow increases type II collagen deposition and tensile mechanical properties in bioreactor-grown tissue-engineered cartilage. Tissue Eng. 2006; 12: 469-479. Ref.: https://tinyurl.com/ycumwcv8

77. Chen S, Wang $S$, Xie T. Restricting self-renewal signals within the stem cell niche: multiple levels of control. Curr Opin Genet Dev. 2011; 21: 684-689. Ref.: https://tinyurl.com/y6uzyvbz

78. Brizzi MF, Tarone G, Defilippi P. Extracellular matrix, integrins, and growth factors as tailors of the stem cell niche. Curr Opin Cell Biol. 2012; 24: 645-651. Ref.: https://tinyurl.com/yaa6fd2r

79. Kuster MS, Wood GA, Stachowiak GW, Gächter A. Joint load considerations in total knee replacement. Journal of Bone and Joint Surgery-British Volume. 1997; 79B: 109-113. Ref.: https://tinyurl.com/y8cy98kp

80. Marlovits S, Tichy B, Truppe M, Gruber D, Vécsei V. Chondrogenesis of aged human articular cartilage in a scaffold-free bioreactor. Tissue Eng. 2003; 9: 1215-1226. Ref.: https://tinyurl.com/y8g6aswf

81. Concaro S, Gustavson F, Gatenholm P. Bioreactors for tissue engineering of cartilage. Adv Biochem Eng Biotechnol. 2009; 112: 125-143. Ref.: https://tinyurl.com/y8ehgrej

82. Korhonen RK, Laasanen MS, Töyräs J, Rieppo J, Hirvonen J. Comparison of the equilibrium response of articular cartilage in unconfined compression, confined compression and indentation. J Biomech. 2002; 35: 903-909. Ref.: https://tinyurl.com/yb77sdvz

83. Buschmann MD, Gluzband YA, Grodzinsky AJ, Hunziker EB. Mechanical compression modulates matrix biosynthesis in chondrocyte agarose culture. J Cell Science. 1995; 108: 1497-1508. Ref.: https://tinyurl.com/ybwlvgqa

84. Sah RL, Doong JY, Grodzinsky AJ, Plaas AH, Sandy JD. Effects of compression on the loss of newly synthesized proteoglycans and proteins from cartilage explants. Arch Biochem Biophys. 1991; 286: 20-29. Ref.: https://tinyurl.com/y7br3kgv

85. Mow VC, Wang CC. Some bioengineering considerations for tissue engineering of articular cartilage. Clin Orthop Relat Res. 1999; 204-223. Ref.: https://tinyurl.com/yatwlpff

86. von Eisenhart R, Adam C, Steinlechner M, Müller-Gerbl M, Eckstein F. Quantitative determination of joint incongruity and pressure distribution during simulated gait and cartilage thickness in the human hip joint. J Orthop Res. 1999; 17: 532-539. Ref.: https://tinyurl.com/ycxqsh8o

87. Davisson T, Kunig S, Chen A, Sah R, Ratcliffe A. Static and dynamic compression modulate matrix metabolism in tissue engineered cartilage. J Orthop Res. 2002; 20: 842-848. Ref.: https://tinyurl.com/y8yxz2wm

88. Huang $\mathrm{CY}$, Hagar $\mathrm{KL}$, Frost $\mathrm{LE}$, Sun $\mathrm{Y}$, Cheung HS. Effects of cyclic compressive loading on chondrogenesis of rabbit bone-marrow derived mesenchymal stem cells. Stem Cells. 2004; 22: 313323. Ref.: https://tinyurl.com/y9z5aybt

89. Terraciano V, Hwang N, Moroni L, Park HB, Zhang Z. Differential response of adult and embryonic mesenchymal progenitor cells to mechanical compression in hydrogels. Stem Cells. 2007; 25: 2730 2738. Ref.: https://tinyurl.com/ycebr2vz 
90. Huang $\mathrm{CY}$, Reuben PM, Cheung HS. Temporal expression patterns and corresponding protein inductions of early responsive genes in rabbit bone marrow-derived mesenchymal stem cells under cyclic compressive loading. Stem Cells. 2005; 23: 1113-1121. Ref.: https://tinyurl.com/ybvhum6u

91. Campbell JJ, Lee DA, Bader DL. Dynamic compressive strain influences chondrogenic gene expression in human mesenchymal stem cells. Biorheology. 2006; 43: 455-470. Ref.: https://tinyurl.com/ybzfx4fk

92. Bian L, Fong JV, Lima EG, Stoker AM, Ateshian GA. Dynamic mechanical loading enhances functional properties of tissue-engineered cartilage using mature canine chondrocytes. Tissue Eng Part A. 2010; 16: 1781-1790. Ref.: https://tinyurl.com/yd2zeah9

93. Poole AR, Kojima T, Yasuda T, Mwale F, Kobayashi M. Composition and structure of articular cartilage: a template for tissue repair. Clin Orthop Relat Res. 2001; 391: S26-33. Ref.: https://tinyurl.com/ycz7hgtg

94. Mizuno S, Tateishi T, Ushida T, Glowacki J. Hydrostatic fluid pressure enhances matrix synthesis and accumulation by bovine chondrocytes in three-dimensional culture. J Cell Physiol. 2002. 193: 319327. Ref.: https://tinyurl.com/yaglk592

95. Meyer EG, Buckley CT, Steward AJ, Kelly DJ. The effect of cyclic hydrostatic pressure on the functional development of cartilaginous tissues engineered using bone marrow derived mesenchymal stem cells. Journal of the Mechanical Behavior of Biomedical Materials. 2011; 4: 1257-1265. Ref.: https://tinyurl.com/y9mnzgo3

96. Hansen U, Schünke M, Domm C, loannidis N, Hassenpflug J, et al. Combination of reduced oxygen tension and intermittent hydrostatic pressure: a useful tool in articular cartilage tissue engineering Journal of Biomechanics. 2001; 34: 941-949. Ref.: https://tinyurl.com/ydxomvvq

97. Hu JC, Athanasiou KA. The effects of intermittent hydrostatic pressure on self-assembled articular cartilage constructs. Tissue Engineering. 2006; 12: 1337-1344. Ref.: https://tinyurl.com/ya4zkgql

98. Ogawa R, Mizuno S, Murphy GF, Orgill DP. The effect of hydrostatic pressure on three-dimensional chondroinduction of human adipose-derived stem cells. Tissue Engineering Part A. 2009; 15: 29372945. Ref.: https://tinyurl.com/y992o3me

99. Luo ZJ, Seedhom BB. Light and low-frequency pulsatile hydrostatic pressure enhances extracellular matrix formation by bone marrow mesenchymal cells: an in-vitro study with special reference to cartilage repair. Proc Inst Mech Eng H. 2007; 221: 499-507. Ref.: https://tinyurl.com/y8czmnam

100. Miyanishi K, Trindade MC, Lindsey DP, Beaupré GS, Carter DR. Effects of hydrostatic pressure and transforming growth factor-beta 3 on adult human mesenchymal stem cell chondrogenesis in vitro. Tissue Engineering. 2006. 12: 1419-1428. Ref.: https://tinyurl.com/y8pgwyv2

101. Seidel JO, Pei M, Gray ML, Langer R, Freed LE. Long-term culture of tissue engineered cartilage in a perfused chamber with mechanical stimulation. Biorheology. 2004; 41: 445-458. Ref.: https://tinyurl.com/y88wsnjt

102. Wimmer MA, Grad S, Kaup T, Hänni M, Schneider E. Tribology approach to the engineering and study of articular cartilage. Tissue Eng. 2004. 10: 1436-1445. Ref.: https://tinyurl.com/ydcvz9xw

103. Wimmer MA, Alini M, Grad S. The effect of sliding velocity on chondrocytes activity in 3D scaffolds. J Biomech. 2009; 42: 424-429. Ref.: https://tinyurl.com/y8r68cg6

104. van Donkelaar CC, Schulz RM. Review on patents for mechanical stimulation of articular cartilage tissue engineering. Recent Patents on Biomedical Engineering. 2008; 1: 1-12. Ref.: https://tinyurl.com/ycm36q77

105. Nazempour A, Quisenberry CR, Van Wie BJ, Abu-Lail NI. Nanomechanics of engineered articular cartilage: synergistic influences of transforming growth factor- $\beta 3$ and oscillating pressure. $J$ Nanoscience Nanotechnology. 2016; 16: 3136-3145. Ref.: https://tinyurl.com/ybx4obv2

106. Quisenberry CR, Nazempour A, Van Wie BJ, Abu-Lail NI. Expression of N-Cadherins on Chondrogenically Differentiating Human Adipose Derived Stem Cells Using Single-Molecule Force Spectroscopy. J Nanomedicine Res. 2016; 3: 1-13. Ref.: https://tinyurl.com/y8k9q9ml

107. Quisenberry CR, Nazempour A, Van Wie BJ, Abu-Lail NI. Evaluation of $\beta 1$-integrin expression on chondrogenically differentiating human adipose-derived stem cells using atomic force microscopy. Biointerphases. 2016; 11: 021005. https://tinyurl.com/y8b3h5v8

108. Hao H, Chen G, Liu J, Ti D, Zhao Y, et al. Culturing on Wharton's jelly extract delays mesenchymal stem cell senescence through p53 and p16INK4a/pRb pathways. Plos One. 2013; 8: 13. Ref.: https://tinyurl.com/y8gunpuf

109. Nazempour A, Quisenberry, CR, Abu-Lail, NI, Van Wie BJ. Combined effects of oscillating hydrostatic pressure, perfusion and encapsulation in a novel bioreactor for enhancing extracellular matrix synthesis by bovine chondrocytes. Cell Tissue Res. 2017; 7: 017-2651. 
110. Kawanishi M, Oura A, Furukawa K, Fukubayashi T, Nakamura K, et al. Redifferentiation of dedifferentiated bovine articular chondrocytes enhanced by cyclic hydrostatic pressure under a gas-controlled system. Tissue Eng. 2007; 13: 957-964. Ref.: https://tinyurl.com/y8t9z766

111. Gharravi AM, Orazizadeh $M$, Hashemitabar M. Fluid-induced low shear stress improves cartilage like tissue fabrication by encapsulating chondrocytes. Cell Tissue Bank. 2015; 17: 117-122. Ref.: https://tinyurl.com/y6uo3dhm

112. Benya PD, Shaffer JD. Dedifferentiated chondrocytes reexpress the differentiated collagen phenotype when cultured in agarose gels. Cell. 1982; 30: 215-224. Ref.: https://tinyurl.com/ y98nldre

113. Kessler MW, Grande DA. Tissue engineering and cartilage. Organogenesis. 2008; 4: 28-32. Ref.: https://tinyurl.com/y9gf5u26

114. Buschmann MD, Gluzband YA, Grodzinsky AJ, Kimura JH, Hunziker EB. Chondrocytes in agarose culture synthesize a mechanically functional extracellular matrix. J Orthop Res. 1992; 10: 745-758. Ref.: https://tinyurl.com/ybnosqgj

115. Van Wie BJ, Brouns TM, Elliot ML, Davis WC. A novel continuos centrifugal bioreactor for highdensity cultivation of mammalian and microbial-cells. Biotechnol Bioeng. 1991; 38: 1190-1202. Ref.: https://tinyurl.com/y8lghg32

116. Detzel CJ, Van Wie BJ. Use of a centrifugal bioreactor for cartilaginous tissue formation from isolated chondrocytes. Biotechnology Progress. 2011; 27: 451-459. Ref.: https://tinyurl.com/y873ggwy

117. Van Wie BJ, Elliott ML, Lee JM, Scott CD. Development and characterization of a continuous centrifugal bioreactor. 1986. Ref.: https://tinyurl.com/y7yal3jm

118. Mauck RL, Nicoll SB, Seyhan SL, Ateshian GA, Hung CT. Synergistic action of growth factors and dynamic loading for articular cartilage tissue engineering. Tissue Engineering. 2003; 9: 597-611. Ref.: https://tinyurl.com/y9jonhz5

119. Sophia Fox AJ, Bedi A, Rodeo SA. The basic science of articular cartilage: structure, composition, and function. Sports Health. 2009; 1: 461-468. Ref.: https://tinyurl.com/ybj2bu9y

120. Kesti $M$, Müller $M$, Becher J, Schnabelrauch M, D'Este $M$. A versatile bioink for three-dimensional printing of cellular scaffolds based on thermally and photo-triggered tandem gelation. Acta Biomater. 2015; 11: 162-172. Ref.: https://tinyurl.com/y7zlq4y6

121. Das S, Pati F, Choi YJ, Rijal G, Shim JH, et al. Bioprintable, cell-laden silk fibroin-gelatin hydrogel supporting multilineage differentiation of stem cells for fabrication of three-dimensional tissue constructs. Acta Biomater. 2015; 11: 233-246. Ref.: https://tinyurl.com/y95kcppj

122. Shoichet MS, Li RH, White ML, Winn SR. Stability of hydrogels used in cell encapsulation: An in vitro comparison of alginate and agarose. Biotechnol Bioeng. 1996; 50: 374-381. Ref.: https://tinyurl.com/yd8q3ltf

123. Smith CM, Stone AL, Parkhill RL, Stewart RL, Simpkins MW, et al. Three-dimensional bioassembly tool for generating viable tissue-engineered constructs. Tissue Eng. 2004; 10: 1566-76. Ref.: https://tinyurl.com/y9dlduvu

124. Nazempour A, Van Wie BJ. Chondrocytes, mesenchymal stem sells, and their combination in articular cartilage regenerative medicine. Annals of Biomedical Engineering. 2016; 44: 1325-1354. Ref.: https://tinyurl.com/ydyjukdj

125. Scaglione $S$, Wendt $D$, Miggino $S$, Papadimitropoulos $A$, Fato $M$, et al. Effects of fluid flow and calcium phosphate coating on human bone marrow stromal cells cultured in a defined $2 \mathrm{D}$ model system. J Biomed Mater Res A. 2008; 86: 411-419. Ref.: https://tinyurl.com/ybdqy8h7

126. Kreke MR, Huckle WR, Goldstein AS. Goldstein. Fluid flow stimulates expression of osteopontin and bone sialoprotein by bone marrow stromal cells in a temporally dependent manner. Bone, 2005; 36: 1047-1055. Ref.: https://tinyurl.com/ybe9rl7q

127. Kapur S, Baylink DJ, Lau KH. Fluid flow shear stress stimulates human osteoblast proliferation and differentiation through multiple interacting and competing signal transduction pathways. Bone. 2003; 32: 241-251. Ref.: https://tinyurl.com/ydyo7ses

128. Lee SH, Shin H. Matrices and scaffolds for delivery of bioactive molecules in bone and cartilage tissue engineering. Advanced Drug Delivery Reviews. 2007; 59: 339-359. Ref.: https://tinyurl.com/ycc5orob

129. Ecker DM, Jones SD, Levine HL. The therapeutic monoclonal antibody market. MAbs. 2015; 7: 9-14. Ref.: https://tinyurl.com/ycdchsan

130. Detzel CJ, Mason DJ, Davis WC, van Wie BJ. Kinetic simulation of a centrifugal bioreactor for high population density hybridoma culture. Biotechnol Prog. 2009; 25: 1650-1659 